\title{
EFFECT OF PRE-HEATING ON HARDNESS, FLEXURAL PROPERTIES AND DEPTH OF CURE OF DENTAL TWO RESIN COMPOSITES
}

\author{
Gehan A. Elolimy*
}

\begin{abstract}
Background: It has been observed that preheating dental composites prior to photo-curing improves their handling characteristics and enhances their mechanical properties.

Aim: This study aimed to investigate the effect of three preheating temperatures on hardness, flexural strength and depth of cure of Filtek ${ }^{\mathrm{TM}}$ Z250 XT Nano Hybrid and Filtek ${ }^{\mathrm{TM}}$ P60 Packable composites.
\end{abstract}

Materials \& Methods: a total of 90 composite specimens were prepared 30 for each temperature and the samples were preheated at 24,54 and $68{ }^{\circ} \mathrm{C}$. Vickers microhardness, flexure strength/modulus and depth of cure of preheated samples were recorded for both materials. For each test, thirty specimens for each resin composite were prepared and randomly divided in 3 subgroups (10 for each) according to the preheating temperature. Statistical analysis was carried out using One-Way ANOVA.

Results: Increasing the preheating temperature of Filtek ${ }^{\mathrm{TM}}$ Z250 XT Nano-hybrid and Filtek ${ }^{\mathrm{TM}}$ P60 packable composites significantly increased the Vickers microhardness number, flexure strength and depth of cure. This effect was prominent particularly when the temperature increased from 24 to $54^{\circ} \mathrm{C}$. Filtek ${ }^{\mathrm{TM}} \mathrm{P} 60$ packable composites showed significantly higher Vickers microhardness number, flexure strength/modulus and depth of cure than Filtek ${ }^{\mathrm{TM}}$ Z250 XT Nano-hybrid at the tested preheating temperatures.

Conclusion: preheating improved the hardness, flexure properties and depth of cure of tested composites.

KEY WORDS: Composite resin- Nanohybrid- Packable- preheating

* Lecturer of Dental Biomaterials, Department of Dental Biomaterials, Faculty of Dentistry, Tanta University, Tanta, Egypt. 


\section{INTRODUCTION}

Composite resins are widely used in dental restorations as minimally invasive and esthetically pleasing to the patient. Since their commercialization in the 1960's, there is an ongoing effort to improve their clinical behavior by modifying the filler and resin matrix used ${ }^{[1,2]}$.

Highly filled Micro- and Nanohybrid resin composites have been commonly used with longterm success for load bearing applications. During their placement, however, it is difficult to extrude from compules or syringes. Furthermore, poor adaptation to cavity walls and margin and voids within the bulk of the material will therefore be expected. To improve adaptation and reduce microleakage associated with posterior resin composite restorations, some authors have suggested placing a layer of flowable composites underneath the more highly filled material. However, due to the higher resin content of flowable composite materials, larger polymerization stress is anticipated relative to standard resin composites ${ }^{[3,4]}$

It has been observed that preheating dental composites prior to photo-curing improves their handling characteristics and enhances their marginal adaptation. Furthermore, preheating enhances both radical and monomer mobility resulting in higher degree of monomer conversion which in turn improves the physical and mechanical properties of dental composites ${ }^{[5,6]}$. Calset warmer is one of the most commonly used methods introduced to the market to warm composite resin before placement in the cavity ${ }^{[7]}$. The manufacturer of this device claims that increasing the temperature of the resin before curing resulted in a significant decrease in curing time (up to 80\%) and increased the degree of cure. Also, handling characteristics are said to be improved, allowing the composite to perform more like a flowable resin, while maintaining the properties of the original composite ${ }^{[8]}$

One of the major drawbacks of composite resin is the extent to which they cure which is proportional to the amount of light to which they are exposed. Thus, they polymerize to a certain depth which varies with the penetration of a light beam in the bulk material. This extent of cure has been termed (depth of cure) and has significant influence on mechanical and biological properties of restorations ${ }^{[9]}$. Microhardness has been used to evaluate the mechanical properties of restorative materials, and this property correlates well with the degree of conversion of resin composites ${ }^{[10,11]}$. Therefore, it has been used to evaluate the degree of polymerization indirectly ${ }^{[12]}$

Failure stress of a material is called flexural strength and the stiffness of a material is called flexural modulus as both measured in bending [13]. Flexural strength is important for composite designers because composite resins, especially cavities under stress, are exposed to tension and compression forces ${ }^{[14,15]}$.

This study aimed to investigate the effect of preheating temperatures on Vickers micro-hardness, flexure strength and flexural modulus as well as depth of two types of resin composites.

\section{MATERIALS \& METHODS}

Materials used in this study were: Filtek ${ }^{\mathrm{TM}} \mathrm{Z} 250$ XT (Nano Hybrid, 3M ESPE, St Paul, MN, USA) and Filtek ${ }^{\mathrm{TM}}$ P60 (Packable, 3M ESPE, St Paul, MN, USA).

Specimen preparation: A total of 180 composite resin specimens, 90 specimens for each resin composite were prepared and randomly divided in 3 subgroups $(\mathrm{n}=10)$ according to the preheating temperature for each test as follow: Subgroup 1: (control group) the composites were left in $24^{\circ}$ $\mathrm{C}$ for 24 hours, subgroup $2=$ preheating at $54^{\circ} \mathrm{C}$ and subgroup $3=$ preheating at $68^{\circ} \mathrm{C}$ by $($ Calset TM Ad Dent, Inc. Danbury, CT, USA) Which was preset to 54 or $68{ }^{\circ} \mathrm{C}$. Following preheating, the specimens were cured with quartz-tungsten-halogen light-curing unit (Elipar TM 3M ESPE Grafenau, Germany) for $20 \mathrm{~s}$ according to the manufacturer's instructions. 
TABLE (1) The materials classification and composition

\begin{tabular}{|c|c|c|c|}
\hline Material & Matrix composition & Filler (vol\%) / particle size & Filler composition \\
\hline Filtek $^{\mathrm{TM}} \mathrm{Z} 250 \mathrm{XT}$ & $\begin{array}{l}\text { Bis-GMA, Bis-EMA, UDMA, } \\
\text { TEGDMA Comphorquinon }\end{array}$ & $60 \% / 0.01-3.5 \mu \mathrm{m}$ & Zirconia and silica \\
\hline Filtek $^{\mathrm{TM}} \mathrm{P} 60$ & $\begin{array}{l}\text { Bis-GMA, Bis-EMA, UDMA, } \\
\text { TEGDMA }\end{array}$ & $61 \% / 0.01-3.5 \mu \mathrm{m}$ & $\begin{array}{l}\text { Aluminum oxide, silica, } \\
\text { zirconium oxide }\end{array}$ \\
\hline
\end{tabular}

\section{Vickers Microhardness}

30 discs for each composite type, for each temperature $(n=10)$ were prepared using split Teflon molds with dimensions $6 \mathrm{~mm}$ in diameter and $2 \mathrm{~mm}$ in height. The resin composite was packed in the split Teflon mold using Teflon coated plastic filling instrument. A polyester strip was placed over the material and a glass slab was placed over the mold to obtain a flat surface. The glass slab was then removed and the light cure was placed directly onto the polyester strip touching it for 20 seconds according to manufacturer instructions. After the photo-activation, the samples were removed from the Teflon molds and their surface was polished with \# 150, \# 400, \# 600, \# 1200, and \# 2000 grit waterproof abrasive papers. Then, they were immersed in distilled water at $37^{\circ} \mathrm{C}$, and placed into a dark container for 24 hours. ${ }^{[16,17]}$

Vickers micro-hardness test was performed using Vickers micro-hardness indenter (ZwicRoell, west Midlands, England) using a $100 \mathrm{gm}$ load with a dwell time of 15 seconds. Three readings were recorded for the top surfaces of each specimen used and the three indentations made by the square based diamond indenter of angle 136, the mean value was calculated for each specimen. Vickers hardness number (VHN) was calculated by the following equation ${ }^{[18]}$ VHN: $\mathbf{H V}=\mathbf{1 . 8 5 4} \mathbf{P} / \mathbf{d} 2$

Where, HV was Vickers hardness in $\mathrm{Kgf} / \mathrm{mm} 2$, $\mathrm{P}$ was the load applied in Kgf and d was the length of the diagonals in $\mathrm{mm}$ and 1.854 was a constant number.

\section{Flexural Strength and flexural Modulus}

For this test, flat bars of $25 \times 2 \times 2 \mathrm{~mm}^{3}$ were prepared using Teflon mold [19]. Thirty specimens of composite resin, subgroup $(n=10)$ were used. Following insertion and adaptation of the composite resin, the surface of composite was covered with a Mylar matrix to avoid oxygen inhibition layer. A glass-slide was then placed on top of the Mylar strip and held in place by finger pressure to exude excess materials and render the surface flat. Samples were then cured with three times of light exposures to cure the entire length of specimen. After light curing, all specimens were stored in distilled water for $24 \mathrm{~h}$ at $37^{\circ} \mathrm{C}$. A 3-point bending test was conducted using the universal testing machine (Instron 3600 series, USA) at a crosshead speed $0.5 \mathrm{~mm} / \mathrm{min}$. Prior to testing, samples dimensions were measured using a micrometer accurate to 0.01 mm (Digimatic QuantuMike Micrometer; Mitutoyo Corp., Kawasaki, Japan). The flexural strength was computed from: $\mathrm{S}=\mathbf{3} \mathbf{F}$ I $/ \mathbf{2} \mathbf{b}^{2}$ where:

$\mathrm{S}$ : Flexural strength, in MPa.

F: Maximum load before fracture, in Newton.

I : Distance between supports, $20 \mathrm{~mm}$.

b : Width of the specimen, $2 \mathrm{~mm}$.

$\mathrm{d}$ : Thickness of the specimen, $2 \mathrm{~mm}$.

Flexural modulus was calculated from $\mathbf{E}=\mathbf{I}^{\mathbf{3}} \mathbf{F} / \mathbf{4} \mathbf{b h}^{\mathbf{3}} \mathbf{d}$ where:

E: Flexural modulus, in GPa.

I : Distance between supports, $\mathrm{mm}$. 
F: Maximum load before fracture, in Newton.

$\mathrm{h}$ : Hight of the specimen, $\mathrm{mm}$.

$\mathrm{d}$ : the deflection, in $\mathrm{mm}$

\section{Depth of Cure}

Depth of cure was tested according to ISO 4049 [19]. This method measures the height length of the remaining set hardened material after scrapping away the unset soft material. A stainless steel mold of $8 \mathrm{~mm}$ long and $4 \mathrm{~mm}$ diameter was placed on a glass slide covered by a Mylar strip (Hawe Stopstrip Straight, KerrHawe, Bioggio, Switzerland). The mold was then filled in bulk with_one of the tested resin composites. The top side of the mold was then covered with a second Mylar strip and the resin material made flushed with the mold by use of a second glass slide. Then the mold was placed on a white filter paper (Filter Paper Circles 589/1,Schleicher \& Schuell MicroScience GmbH, Dassel, Germany). The second glass slide was removed and the resin composite was light-cured for either $20 \mathrm{~s}$ according to manufacturer instructions keeping the light tip centered and in contact with the second Mylar strip. After light-curing, the cylindrical specimens were pushed out from the mold and the uncured composite resin material was removed with a plastic spatula. The absolute length of the cylindrical specimens of cured resin composite was then measured with a digital caliper of $\pm 0.01 \mathrm{~mm}$ accuracy (Mitutoyo IP 65, Kawasaki, Japan). Depth of cure is then calculated as $50 \%$ of the remaining hardened specimen height.

\section{Statistical Analysis}

One-Way ANOVA test was used to test the significant difference between the groups. The t-test was used to compare the mean of Filtek ${ }^{\mathrm{TM}}$ Z250 XT and Filtek ${ }^{\mathrm{TM}} \mathrm{P} 60$ at each preheating temperature. This was carried out using IBM SPSS software package version 20.0 .

\section{RESULTS}

\section{Vickers Micro-hardness}

The mean and standard deviation of Vickers micro-hardness numbers for each composite are given in Table (2). As observed from Table 1, the highest value for both types of composites was at $68^{\circ} \mathrm{C}$ however, the lowest one was at $24^{\circ} \mathrm{C}$. The mean value of Vickers micro-hardness increased significantly with increasing the preheating temperature from 24 to $54{ }^{\circ} \mathrm{C}$. This finding was observed for Nano-hybrid Z250 XT and Filtek ${ }^{\mathrm{TM}}$ P60 packable composites. Further increase in temperature to $68^{\circ} \mathrm{C}$ produced no significant change in Vickers micro-hardness number. Generally, it has been observed that Filtek ${ }^{\mathrm{TM}}$ P60 showed significantly higher hardness than Filtek ${ }^{\mathrm{TM}}$ Z250 $\mathrm{XT}$ at tested temperatures.

\section{Flexure Strength}

Table (3) shows the mean and standard deviation of flexural strength of tested composite resins at different preheating temperatures. As observed, the highest value for both composite types was

TABLE (2): Mean \pm SD of Vickers Microhardness number (VHN) of composite samples subjected to different preheating temperatures.

\begin{tabular}{|l|l|l|l|l|l|}
\hline Materials & $\mathbf{2 4}^{\circ} \mathbf{C}$ & $\mathbf{5 4}^{\circ} \mathbf{C}$ & $\mathbf{6 8}^{\mathbf{}} \mathbf{C}$ & ANOVA & P value \\
\hline Filtek $^{\mathrm{TM}} \mathrm{Z} 250 \mathrm{XT}$ & $49.3 \pm 1.14^{\mathrm{A}}$ & $51.1 \pm 0.64^{\mathrm{B}}$ & $52.2 \pm 0.86^{\mathrm{B}}$ & 13.768 & $0.001^{*}$ \\
\hline Filtek $^{\mathrm{TM}} \mathrm{P} 60$ & $78.14 \pm 0.56^{\mathrm{A}}$ & $84.34 \pm 1.08^{\mathrm{B}}$ & $85.34 \pm 1.01^{\mathrm{B}}$ & 89.876 & $0.001^{*}$ \\
\hline T test & 50.54 & 58.61 & 55.33 & & \\
\cline { 1 - 4 } P value & $0.001^{*}$ & $0.001^{*}$ & $0.001^{*}$ & &
\end{tabular}

Different letters mean that there is significant difference in the same raw at $P$ value $\leq 0.001$. 
at $68^{\circ} \mathrm{C}$ and the lowest value was at $24^{\circ} \mathrm{C}$, there is a significant increase in flexure strength with increasing the preheating temperature. This finding was observed for both Nano-hybrid Z250 XT and Filtek $^{\text {TM }}$ P60 packable composites. Generally, it has been observed that Filtek ${ }^{\mathrm{TM}}$ P60 showed significantly higher flexure strength than Filtek ${ }^{\mathrm{TM}}$ $\mathrm{Z} 250 \mathrm{XT}$ at tested temperatures.

Table 4 shows the mean and standard deviation of flexural modulus of tested composite resins at different preheating temperatures. As observed, the highest value for both composite types was at $68^{\circ} \mathrm{C}$ and the lowest value was for Filtek ${ }^{\mathrm{TM}} \mathrm{Z} 250 \mathrm{XT}$ at $24^{\circ} \mathrm{C}$ however, that of the Filtek ${ }^{\mathrm{TM}} \mathrm{P} 60$ was at $54^{\circ} \mathrm{C}$, the mean flexural modulus of Nano-hybrid Z250 XT and Filtek ${ }^{\mathrm{TM}}$ P60 was not significantly affected by increasing the preheating temperature from 24 to $54{ }^{\circ} \mathrm{C}$. The flexure modulus of both composites were significantly increased by increasing the temperature to $68{ }^{\circ} \mathrm{C}$. Generally, it has been observed that Filtek ${ }^{\mathrm{TM}}$ P60 showed significantly higher flexure modulus than Filtek ${ }^{\mathrm{TM}}$ Z250 XT at tested temperatures.

\section{Depth of Cure}

Table 5 shows the mean and standard deviation of depth of cure of the tested composite resins at different preheating temperatures. As seen from Table 4, the highest value for both composite types was at $68^{\circ} \mathrm{C}$ and the lowest value was at $24^{\circ} \mathrm{C}$, the mean depth of cure of Nano-hybrid Z250 XT composite was significantly increased by increasing the temperature from 24 to $54{ }^{\circ} \mathrm{C}$. Further increase in temperature to $68{ }^{\circ} \mathrm{C}$, however, produced no significant change. For Filtek ${ }^{\mathrm{TM}}$ P60 packable composite, there is a significant increase in depth of cure with increasing the preheating temperature. Generally, it has been observed that Filtek ${ }^{\mathrm{TM}}$ P60 showed significantly higher depth of cure than Filtek $^{\mathrm{TM}} \mathrm{Z} 250 \mathrm{XT}$ at tested temperatures.

TABLE (3): Mean \pm SD of flexure strength (MPa) of composite samples subjected to different preheating temperatures.

\begin{tabular}{|c|c|c|c|c|c|}
\hline Materials & $24^{\circ} \mathrm{C}$ & $54^{\circ} \mathrm{C}$ & $68^{\circ} \mathrm{C}$ & ANOVA & Pvalue \\
\hline Filtek $^{\mathrm{TM}} \mathrm{Z} 250 \mathrm{XT}$ & $114.21 \pm 2.9^{\mathrm{a}}$ & $123.72 \pm 1.26^{\mathrm{b}}$ & $132.85 \pm 1.1^{\mathrm{c}}$ & 115.862 & $0.001^{*}$ \\
\hline Filtek $^{\mathrm{TM}}$ P60 & $140.42 \pm 0.408^{\mathrm{A}}$ & $141.58 \pm 0.725^{\text {в }}$ & $150.5 \pm 0.605^{\mathrm{C}}$ & 429.857 & $0.001^{*}$ \\
\hline T test & 19.97 & 27.04 & 31.37 & & \\
\hline Pvalue & $0.003^{*}$ & $0.002^{*}$ & $0.001^{*}$ & & \\
\hline
\end{tabular}

Different letters mean that there is a significant difference in the same raw at $P$ value $\leq 0.05$.

TABLE (4): Mean \pm SD of flexure modulus (MPa) of composite samples subjected to different preheating temperatures.

\begin{tabular}{|c|c|c|c|c|c|}
\hline Materials & $24^{\circ} \mathrm{C}$ & $54^{\circ} \mathrm{C}$ & $68^{\circ} \mathrm{C}$ & ANOVA & Pvalue \\
\hline Filtek $^{\mathrm{TM}} \mathrm{Z} 250 \mathrm{XT}$ & $6.63 \pm 0.558^{\mathrm{a}}$ & $6.18 \pm 0.162^{\mathrm{a}}$ & $8.3 \pm 1.26^{\mathrm{c}}$ & 9.609 & $0.03^{*}$ \\
\hline Filtek $^{\mathrm{TM}}$ P60 & $9.63 \pm 0.813^{\mathrm{A}}$ & $8.76 \pm 1.12^{\mathrm{A}}$ & $10.88 \pm 0.655^{\mathrm{C}}$ & 7.95 & $0.04^{*}$ \\
\hline T test & 6.787 & 5.047 & 4.212 & & \\
\hline Pvalue & $0.03^{*}$ & $0.04^{*}$ & $0.04^{*}$ & & \\
\hline
\end{tabular}

Different letters mean that there is a significant difference in the same raw at $P$ value $\leq 0.05$. 
TABLE (5): Mean \pm SD of depth of cure of composite samples (mm) subjected to different preheating temperatures.

\begin{tabular}{|l|l|l|l|l|l|}
\hline Materials & $\mathbf{2 4}^{\circ} \mathbf{C}$ & $\mathbf{5 4}^{\circ} \mathbf{C}$ & $\mathbf{6 8}^{\circ} \mathbf{C}$ & ANOVA & P value \\
\hline Filtek $^{\mathrm{TM}} \mathrm{Z} 250 \mathrm{XT}$ & $2.12 \pm 0.286^{\mathrm{a}}$ & $2.64 \pm 0.207^{\mathrm{b}}$ & $2.64 \pm 0.207^{\mathrm{b}}$ & 13.768 & $0.06^{*}$ \\
\hline Filtek $^{\mathrm{TM}} \mathrm{P} 60$ & $2.76 \pm 0.167^{\mathrm{A}}$ & $3.134 \pm 0.115^{\mathrm{B}}$ & $3.57 \pm 0.097^{\mathrm{C}}$ & 48.546 & $0.001^{*}$ \\
\cline { 1 - 4 } T test & 4.315 & 4.656 & 9.076 & & \\
\cline { 1 - 3 } P value & $0.03^{*}$ & $0.02^{*}$ & $0.01^{*}$ & &
\end{tabular}

Different letters mean that there is a significant difference in the same raw at $P$ value $\leq 0.05$.

\section{DISCUSSION}

The present study evaluated the effect of preheating on microhardness, flexures properties, and depth of cure of Filtek ${ }^{\mathrm{TM}}$ Z250 XT Nano-hybrid and Filtek ${ }^{\mathrm{TM}}$ P60 packable composites.

As known, the packable composite was invented with the new inter-locking particle technology that relies on the use of a precisely engineered mixture of different-sized filler particles. These particles are 0.01-3.5 $\mu \mathrm{m}$ in size, about $61 \mathrm{vol} \%$ and made of a patented fluoride-infused glass and when they are packed together, the larger particles mechanically interlock with the smaller particles leading to improvement of the depth of cure and microhardness ${ }^{[20]}$.

In Nano-hybrid composites, colloidal silica particles of approximately $40 \mathrm{~nm}$ diameter have been used. Therefore, they have outstanding esthetics and enhanced wear resistance. Nano-hybrid composites may also show an enhanced fracture toughness and adhesion to tooth structures. They also have high durability and low polymerization shrinkage ${ }^{[21]}$.

Advantages of preheating the resin are to reduce the viscosity and provide flow values of the highly viscous composite resin to simulate that of those of less filled flowable composite resins, without affecting the mechanical properties. Also, heating the resin prior to placement is accompanied with increase in monomer conversion and polymerization rate ${ }^{[22,23]}$.

Preheating could be done by using Calset Composite Warmer: is the most popular, widely reported in literature and effective device to preheat dental composite resins ${ }^{[24,25]}$, Therma-Flo ${ }^{\mathrm{TM}}$ composite warmer ${ }^{[26]}$, Light of dental unit or Hand holding as suggested in article by Myoung-Uk $\mathrm{Jin}^{[25]}$, Hot water bath ${ }^{[27]}$, Thermocycling apparatus, Microwave oven or Hair dryer ${ }^{[28]}$, Modified glass bead sterilizer ${ }^{[29]}$ and Wax warmer ${ }^{[30]}$ are also another tools proposed for preheating.

In this study, resin composites were preheated by Calset Composite Warmer and maintained in the device for 5 minutes so as to accomplish the most extreme preset temperature. Preheating at $24^{\circ} \mathrm{C}$ was chosen because this temperature represents the typical dental office temperature; it was observed that, by placing composite resin preheated to $54.5^{\circ} \mathrm{C}$, the temperature rise of pulp tissue was only $2.4 \pm 0.3^{\circ} \mathrm{C}$. Such a temperature rise would suggest that the composite could be inserted with relative safety ${ }^{[31]}$. And $68^{\circ} \mathrm{C}$ represents the maximum temperature can be tolerated.

Regardless of the resin composite material used, Vickers micro-hardness number, flexure properties and depth of cure were significantly improved with increasing the preheating temperatures particularly 
from 24 to $54^{\circ} \mathrm{C}$. It has been observed in other studies that increasing the preheating temperature reduces the viscosity of composite resins; the enhanced mobility of both monomer and polymer at high temperatures could delay the vitrification process. An enhanced degree of monomer conversion and cross-linking will be expected with preheated resin composites. This could explain the increase in Vicker microhardness number, flexure properties and depth of cure observed with increasing the preheating temperature ${ }^{[32,33]}$.

These results agreed with previous researches done by Dionysopoulos et al., ${ }^{[34]}$ Theodoridis et al., ${ }^{[35]}$ who concluded that preheating composite resin to $55^{\circ} \mathrm{C}$ significantly increased the micro-hardness of composite resin. Also, agreed with Ayub et al., ${ }^{[18]}$ who resulted in preheating composite resin enhanced the degree of conversion. Increasing the temperature reduces the viscosity, raises the liquidity, enhances free radical mobility, and increases collision frequency between the active group and free radicals. As a result, the degree of conversion improves, and this evidence is expressed by the increased microhardness of the composite material ${ }^{[36]}$.

The flexural strength results of the present study agreed with these of Kramer et al., ${ }^{[37]}$ and Sharafeddin et al., ${ }^{[38]}$ who reported significantly higher flexural strength values after preheating of tested composite resin compared to non-preheated control group. However, they are disagreed with the research work by Fróes-Salgado et al., ${ }^{[39]}$ and Uctasli et al., ${ }^{[40]}$ that showed that no statistically significant improving effect due to preheating of resin composites.

As regard to depth of cure for the tested composite resin materials it was found that, there is a significant increase in depth of cure with increasing the preheating temperature that could be explained as preheating decreases the viscosity of the resin composites ${ }^{[41]}$ this together with, in the tested Filtek resin composite, the fillers are a combination of a non-agglomerated /non-aggregated silica filler, zirconia filler, and a ytterbium trifluoride filler ${ }^{[42,43]}$. Moreover, it was formulated with aromatic resins, which allowed the refractive index to more closely match the filler so the light would not scattered, and successfully transmitted through the material that increased the material's depth of cure ${ }^{[44]}$.

Generally, it has been observed that Filtek ${ }^{\mathrm{TM}}$ P60 (packable type) showed significantly higher depth of cure than Filtek ${ }^{\mathrm{TM}}$ Z250 XT (nanohybride type) at tested temperatures. This may be attributed to the interlocking particle technology used in the fabrication of the packable composite, where elongated fibrous filler particles of about 100 micron in length, and/or textured surfaces tend to interlock and resist flow. Rough surfaces, blends of fibrous and particulate fillers produce a packable consistency and enable physical and mechanical properties to be optimized for clinical performance ${ }^{[45]}$. Our results are agreed with Carlos et al., ${ }^{[46]}$ who concluded that increasing the temperature significantly increase the depth of cure. As preheating resin composites with a commercially available (Calset) composite warmer increase the monomer conversion rate and increases the depth of cure and hardness of the tested composites.

\section{CONCLUSION}

Increasing the preheating temperature of Filtek ${ }^{\mathrm{TM}}$ Z250 XT Nano-hybrid and Filtek ${ }^{\mathrm{TM}}$ P60 packable composites significantly increased the Vickers microhardness number, flexure properties and depth of cure. This effect was prominent particularly when the temperature increased from 24 to $45^{\circ} \mathrm{C}$. Filtek ${ }^{\mathrm{TM}}$ P60 packable composites showed significantly higher Vickers microhardness value, flexure properties and depth of cure than Filtek ${ }^{\mathrm{TM}}$ Z250 XT Nano-hybrid at the tested preheating temperatures. 


\section{REFERENCES}

1. Gopinathan AS, Jeeva P P, Vinayakumar T. Comparative evaluation of the Vickers micro-hardness and depth of cure of selected dental composites. An In vitro study. Gjra global journal for research analysis 2017; 6: 8160-8169.

2. Vesna Miletic. Development of Dental Composites. In: Miletic V. (eds) Dental Composite Materials for Direct Restorations. Springer, Cham 2018; 10.1007/978-3-21960961-4 (eBook).

3. Bayne SC, Thompson JY, Swift Jr, Stamatiades P, Wilkerson M. A characterization of first generation flowable composites. The Journal of the American Dental Association 1998; 129: 567-577.

4. Alshali RZ, Salim NA, Satterthwaite JD, Silikas N Postirradiation hardness development, chemical softening, and thermal stability of bulk-fill andconventional resin-composites. Journal of dentistry 2015; 43: 209-218.

5. Deb S, Di-Silvio L, Mackler HE, Millar BJ. Pre-warming of dental composites. Dental Materials journal 2011; 27: 51-59.

6. Bausch JR, de Lange C, Davidson CL. The influence of temperature on some physical properties of dental composites. Journal of Oral Rehabilitation1981; 8:309-317.

7. Arora V, Arora P, Shammrani AA, Fahmi MK. Devices $\&$ Methods for pre-heating/pre-warming Dental Resin Composites: A Critical Appraisal. Int. J Oral Health Med. Res.2017; 4:52-55

8. Friedman J. Thermally assisted flow and polymerization of composite resins. Contemp. Esthet. Rest. Pract. 2003;2: $46-52$

9. Lelaoup G, Holoet EP, Beoelman S, Devaux J. Raman Scattering Determination of the depth of cure of light activated composites. J. Oral Rehabil. 2002; 29:510-515

10. Munoz CA, Bond PR, Sy-Munoz J, Tan D, Peterson J. Effect of pre-heating on depth of cure and surface hardness of light-polymerized resin composites. Am J Dent. 2008; 21:215-222.

11. Yan YL, Kim YK, Kim KH, Kwon TY. Changes in degree of conversion and micro-hardness of dental resin cements. Operative dentistry Journal 2010; 35: 203-210.

12. Alrahlah A, Silikas N, Watts DC. Post-cure depths of cure of bulk fill dental resin-composites. Dent. Mater. 2014;30:149-154
13. Yap AU, Teoh SH. Comparison of flexural properties of composite restoratives using the ISO and mini-flexural tests. J Oral Rehabil. 2003; 30: 171-177.

14. Eronat N, Candan U, Türkün M. Effects of glass fiber layering on the flexural strength of microfill and hybrid composites. J Esthet Restor Dent 2009; 21: 171-178

15. Manhart J, Kunzelmann KH, Chen HY, Hickel R. Mechanical properties and wear behavior of light-cured packable composite resins. Dent Mater 2000; 16: 33-40.

16. Bala O, Arisu HD, Yikilgan I, Arslan S, Gullu A. Evaluation of surface roughness and hardness of different glass ionomer cements. European journal of dentistry 2012; 6: 79-87.

17. Ozel S. Surface hardness evaluation of different composite resin materials: influence of sports and energy drinks immersion after a short-term period. Journal of Applied Oral Science 2013; 21: 124-131.

18. Ayub KV, Santos Jr, Rizkalla AS, Bohay R , Pegoraro LF, Rubo JH, Santos MJ. Effect of preheating on microhardness and viscosity of 4 resin composites. J Can Dent Assoc. 2014; 80: 191-196.

19. ISO Standard. ISO 4049 Polymer based filling, restorative and luting materials. 3rd edition. International Organization for Standardization 2000; 1-27.

20. Papadogiannisa Y, Lakesb RS, Palaghias G, HelvatjogluAntoniades M, Papadogiannis D. Fatigue of packable dental composites. Dent. Mater. 2007; 23:235-242.

21. Moraes RR, Gonçalves LS, Lancellotti AC, Consani S, Correr-Sobrinho L, Sinhoreti MA. Nanohybrid resin composites: nanofiller loaded materials or traditional microhybrid resins? Operative dentistry Journal 2009; 34: 551-557.

22. Blalock JS, Holmes R, Rueggeberg FA. Effect of temperature on unpolymerized composite resin film thickness. J Prosthet. Dent. 2006; 96:424-432.

23. Deb S, Di Silvio L, Mackler HE, Millar BJ. Pre-warming of dental composites. Dent Mater. J. 2011; 27: 51-59.

24. Lucey S, Lynch C D, Ray N J, Burke F M, Hannigan A. Effect of pre-heating on the viscosity and microhardness of a resin composite. J Oral Rehabil. 2010; 37: 278-282.

25. Myoung-Uk Jin. Prepare the pre-heated composite resin. Restor. Dent. Endod. 2013; 38: 103-104.

26. www.vistadental.com. Vista Dental Products.2200 South Street. Racine, WI 53404 
27. Dimitrios D, Kosmas T, Paris G, Eugenia K. Effect of preheating on the film thickness of contemporary composite restorative materials J Dent. Sci. 2014; 9:313-319.

28. Vipin A, Pooja A, Al Shammrani A, Fahmi MK. Devices \& Methods for pre-heating/prewarming Dental Resin Composites: A Critical Appraisal . Int. J. Oral Health Med. Res. 2017; 4:52-55.

29. Arora P, Arora V, Shamrani A, Fahmi MK. Innovatively Modified Glass bead Sterlizer for Pre-heating / Pre warming of Dental Composite Resins. Acta Scientific Dental Sciences 2017; 1: 31-34.

30. Arora V, Arora P, Shamrani A, Fahmi MK. A New, simple and innovative technique for Pre-heating / Pre-warming of Dental Composite resins in thermal assisted light polymerization technique. J Dent Oral Biol. 2017; 2: 1061. ISSN: 2475-5680.

31. Trujillo M, Newman SM, Stansbury JW. Use of near-IR to monitor the influence of external heating on dental composite photopolymerization. Dent. Mat. J. 2004; 20:766-777.

32. Daronch M, Rueggeberg FA, De Goes MF. Monomer conversion of pre-heated composite. Journal of Dental Research 2005; 84: 663-667.

33. El-Korashy D. Post-gel shrinkage strain and degree of conversion of preheated resin composite cured using different regimens. Operative Dentistry 2010; 35:172-179.

34. Dionysopoulos D, Papadopoulos C, Koliniotou-Koumpia E. Effect of temperature, curing time, and filler composition on surface microhardness of composite resins. J. Conserv. Dent. 2015 Mar-Apr; 18: 114-118.

35. Theodoridis M, Dionysopoulos D, Koliniotou-Koumpia E, Dionysopoulos P ,Gerasimou P. Effect of preheating and shade on surface microhardness of silorane-based composites. Journal of Investigative and Clinical Dentistry 2017; 8:12204-12212.

36. Daronch M, Rueggeberg FA, Moss L, De Goes MF. Clinically relevant issues related to preheating composite. J Esthet. Restor. Dent. 2006; 18: 340-350.
37. Kramer MR, Edelhoff D, Stawarczyk B. Flexural Strength of Preheated Resin Composites and Bonding Properties to Glass-Ceramic and Dentin. Materials. Materials (Basel) 2016; 9:83-90.

38. Sharafeddin AF, Motamedi BM, Fattah CZ. Effect of Preheating and Precooling on the Flexural Strength andModulus of Elasticity of Nanohybrid and Silorane-based Composite. J Dent Shiraz UnivMed Sci. 2015; 16: 224-229

39. Fróes-Salgado NR, Silva LM, Kawano Y, Francci C, Reis A, et al. Composite pre-heating: Effects on marginal adaptation, degree of conversion and mechanical properties. Dent Mater 2010; 26: 908-914.

40. Uctasli MB, Arisub HD, Lasillac LV, Valittud PK. Effect of Preheating on the Mechanical Properties of Resin Composites Eur. J. Dent. 2008; 2:263-268

41. Benetti A, Havndrup-Pedersen C, Honore D, Pedersen M, Pallesen U. Bulk-fill resin composites: polymerization contraction, depth of cure, and gap formation. Operative Dentistry. 2015;40(2):190-200.

42. Pradeep K, Ginjupalli K, Kuttappa MA, Kudva A, Butula R. In vitro comparison of compressive strength of bulkfill composites and nanohybrid composite. World J Dent. 2016; 7:119-22.

43. Fujita K, Ikemi T, Nishiyama N. Effects of particle size of silica filler on polymerization conversion in a light-curing resin composite. Dent Mater 2011; 27:1079-1085.

44. Mahmood AM. Comparison depth of cure of different viscosities bulk fill composite materials. Int J Sci Res 2015; 6:2201-3.

45. Rawls RH, Upshaw EJ. Restorative resins. Phillips' science of dental material 2003; 11th Ed., Chapter 15: 399-441.

46. MuŇoz CA, Bond PR, Sy-MuÑoz J, Daniel T, Peterson J. Effect of pre-heating on depth of cure and surface hardness of light-polymerized resin composites. Am. J. Dent. 2008; 21:215-222. 